\title{
A BIM Approach for the Design of Industrial Warehouses
}

\author{
Rassidatou Abbo ${ }^{*}$, Okpwe Mbarga Richard ${ }^{2}$, Lezin Seba Minsili ${ }^{3}$, Mbondo Jean Marc ${ }^{4}$ \\ ${ }^{1}$ Graduate Student, Department of Civil Engineering, Yaoundé National Advanced School of Engineering, The University of Yaoundé \\ 1, Cameroon \\ ${ }^{2}$ Lecturer, Department of Civil Engineering, Yaoundé National Advanced School of Engineering, the University of Yaoundé 1, \\ Cameroon \\ ${ }^{3}$ Associate Professor, Department of Civil Engineering, Yaoundé National Advanced School of Engineering, The University of \\ Yaoundé 1, Cameroon \\ ${ }^{4}$ Senior Architect, Department Head, Port Asset Mangement Department, DAME, the Port Authority of Kribi, Cameroon
}

\author{
DOI: $\underline{10.36348 / \text { sjce.2022.v06i01.001 }}$ \\ | Received: 28.11.2021 | Accepted: 03.01.2022 | Published: 10.01.2022 \\ *Corresponding author: Rassidatou Abbo \\ Graduate Student, Department of Civil Engineering, Yaoundé National Advanced School of Engineering, The University \\ of Yaoundé 1, Cameroon
}

\section{Abstract}

All around the world, the Building Information Modeling (BIM) is transforming the architecture of engineering design and of construction industry. While it is in an early implementation stage in African Sub-saharan Countries, many construction regulators and project owners are beginning to enforce the BIM application from the project design stage to its commissioning. The aim of this research work is to provide an approach for designing industrial warehouses using $\mathrm{BIM}$ as it was done in the industrial zone of the Kribi Deep Sea port in Cameroon. The proposed methodology is presented in six steps: definition of BIM general requirements, design of the 3D BIM architectural model, sizing of wall and roof for specific requirements, design of the 3D BIM structural model, coordination of 3D BIM models and interference detection and creation of 4D BIM model. Results obtained from the application of BIM on the design of a warehouse, dedicated to preserve the natural and biological essence of cocoa and coffee products in a hostile marine environment, show that this methodology is easily appropriated and implemented by local design and construction engineers through available engineering software in the local market.

Keywords: Design, Warehouses, Construction, BIM model, Port Authority.

Copyright () 2022 The Author(s): This is an open-access article distributed under the terms of the Creative Commons Attribution 4.0 International License (CC BY-NC 4.0) which permits unrestricted use, distribution, and reproduction in any medium for non-commercial use provided the original author and source are credited.

\section{INTRODUCTION}

The Building Information Modeling (BIM) all round the world is widely implemented at different rates for major design and construction projects in accordance with existing norms and standards. Its numerous contributions have pushed stakeholders (Owners, Managers, Designers, Engineers and Contractors) to adopt BIM during all processes related to projects design and construction in Western and Asian countries (Juhee Rho et al., 2021; McAuley et al., 2017; Eastman et al., 2011). This not the case for major projects managed by local engineers in SubSaharan Africa where the spreading of the BIM is just at its early stages (Hanane B. and Dalila L., 2020; Okpwe and Mamba, 2019; Ruya Tambaya et al., 2018).

In Cameroon, at National Advanced School of Engineering of Yaoundé, many research works have been conducted in order to enhance the use of the BIM full potential in construction projects. Precisely, Okpwe (2020) proposed an approach for automatic evaluation of cost and environmental impacts of buildings using BIM objects. Other academics of the NASEY, such as Abanda et al. (2018) and Buhammood et al. (2020), studied the potential of cloud/mobile BIM management of construction projects while coupling BIM and game engine technologies for construction knowledge enhancement.

In this context, our paper aims to propose an approach in order to design industrial warehouses using BIM in the port environment of Cameroon. This approach is subdivided in these main sections namely: the methodology description, the proposed methodology for designing warehouses in Cameroon, a case study for designing a warehouse for the Port 
Authority of Kribi, and obtained results show that this methodology can be easily appropriated and implemented by local design and construction engineers through available engineering software in the local market.

\section{Proposed methodology for the design of warehouses in Cameroon}

The proposed methodology makes use of a BIM level of maturity 2, which corresponds to the collaboration of object-oriented models using 3D modeling software which can perform two-way exchanges (BIM tools and BIM platforms), and is given six mains steps:

- Definition of BIM general requirements;

- Design of architectural BIM model;

- Design of thermal insulation;

- Design of structural BIM model;

- Coordination of 3D BIM models and interference detection;

- Creation of 4D BIM model.

\subsection{Definition of the project requirements}

Definition of BIM requirements is focus on following parameters (Trehen et al., 2016):

- Units of measurement and language used for all models: metric units and French language are selected;

- Open Standard (Open BIM): in order to maintain the greatest flexibility, company does not impose specific modeling software on project teams; they are free to choose the most suitable software for their workflow, however, software must allow the export and import of data in the open format required by company, such as IFC format or BCF format;

- BIM outputs: here, file formats to be used at each stage of project's lifetime are defined. These are:

- $\quad$ Architecture model will be made in Autodesk Revit and saved in ".rvt" format and ".ifc" format;

- Structural model will be produced in Robot Structural Analysis and saved in ".rtd" format;

- Execution schedule of the work will be done in Ms Project and saved in ".mpp" format;

- 4D model will be made in Autodesk Navisworks Manage and saved in ".nwf" format;

- Quantities and quotation will be made in Revit;

- 2D execution plans and calculation notes will be saved in PDF format;

- Definition of LoD (Level of Development): we will make use of a LoD 300.

\subsection{Design of architectural BIM model}

Design of architectural BIM model is made using Revit Architecture 2018 (Daniel John Stine, 2020) by following prescribed requirements for the structural design team in order to link and view the architectural or MEP files.

\subsection{Design thermal insulation}

Evaluation of heat transfers through the walls of the structure will allow us to ensure the quality of the work, in accordance with the needs issued by the client. Thus, we will focus on this component. Since our goal is to minimize heat transfer, we will evolve assuming that the walls are multilayer. Elements (wall and roof) are sized making use of CSTB (1975). Computations are conducted with Microsoft Excel 2010 Software. Results of these computations are introduced into the previous architectural model.

\subsection{Design of structural BIM model}

Basic structural BIM model is imported from Revit 2018 Platform to Robot Structural Analysis 2018. Next, Robot Structural Analysis 2018 is exploited in order to size: structural components of the warehouse (trusses, columns, frames, etc.), foundations, assemblies of structural elements, etc. Final structural BIM model of the warehouse is generated with Robot Structural Analysis 2018, and is exported to Revit 2018 Platform in IFC format in order to update BIM model.

\subsection{Coordination of 3D BIM models and interference detection}

$3 \mathrm{D}$ coordination is part of an overall objective of quality assurance for the development of a concept and the realization of a building. 3D coordination includes visual coordination and coordination by detecting interference between different building systems (Celnik and Lebègue, 2015) and making use use of the Navisworks Simulations (2018), we outdraw the following steps:

- Visual coordination: it is a collaborative process that brings professionals together around a 3D model to get their feedback and validate certain aspects of the design. Visual validation should be used continuously from the beginning of the design phase to the construction phase. It serves as a support for decision-making during the various workshops to follow up on the concept or during workshops. All stakeholders in a project can actively participate in visual coordination through the implementation of a digital collaborative platform.

- Interference detection: it is a process in which interference detection software is used to determine physical conflicts between different construction systems from the 3D models of each discipline, previously grouped together within a federated model. Interference detection is applied during the design phase, because when the concept and modeling are sufficiently advanced and it can be difficult to visually determine conflicts between different systems.

\subsection{Creation of 4D BIM model}

Before we start attaching the elements of the process, we must first import the global model from Revit 2018 Platform to Navisworks Manage 2018 using 
Rassidatou Abbo et al., Saudi J Civ Eng, Jan, 2022; 6(1): 1-8

the IFC format. The "time liner" tab is the feature that will allow us to link the schedule to the 3D model. At this level, we can either create a schedule directly in the software, or import a schedule from Microsoft Project using the "data sources" tab. At the end of this task, we will associate the elements of the model with the schedule thanks to the "attach" tab and specify the task (construction / demolition) that the simulator will have to perform on the element. The "simulate" tab allows us to simulate the construction stages according to the schedule.

\section{Case study of cotton/coffee's warehouse for the Port Authority of Kribi}

This project consists of designing of a warehouse composed of a large storage space (cotton, cocoa or coffee), an office $\left(17.53 \mathrm{~m}^{2}\right)$, a toilet $\left(3.88 \mathrm{~m}^{2}\right)$ and an airlock $\left(9.01 \mathrm{~m}^{2}\right)$. The roof is made of sandwich panels with symmetrical double slopes. There are four (04) openings for pedestrian crossing and eight (08) openings for vehicle way (two (02) and four (04) on the main façade and two (02) and four (04) on the rear façade) as well as windows on the different facades.

The project is located in MBORO (a site of the Port Authority of Kribi, PAK) in South - Cameroon. The building industrial has a surface area of $2000 \mathrm{~m}^{2}$, and is $40 \mathrm{~m}$ wide and $50 \mathrm{~m}$ long, and $11.2 \mathrm{~m}$ total height. The site has the following characteristics:

- Soil type: Decomposed rocks;

- Majority lift class: S5-CEBTP, platform with modulus of elasticity E>150MPA;

- Ground altitude: about $13 \mathrm{~m}$;

- Flat and exposed floor;

- Base pressure: $50 \mathrm{daN} / \mathrm{m}^{2}$.

Thermal requirements of the warehouse are as follows:

- Maximum temperature of the ambient air outside is Text $=35.5^{\circ} \mathrm{C}$ and inside Tint $=23^{\circ} \mathrm{C}$;

- Minimum ambient air temperature outside is Text ${ }^{\prime}$ $=20.4^{\circ} \mathrm{C}$ and inside Tint $^{\prime}=20^{\circ}$;

\subsection{Project requirements}

\section{Regulations}

- CM66 and Addendum 80: Rules for calculating steel constructions;

- $\quad$ EN 1991-4-1 : Eurocode 1- Actions on structure;

- D.T.R C 2.2: Technical document (ongoing and operating expenses);

- BAEL 91: Reinforced concrete in limit states;

- NV 65: Rules determining the actions of snow and wind on buildings;

- DTU 13.12, DTU 13.11: Rules for the calculation of superficial foundations.

- Steels for structural elements: steel is a material by transformation that combines iron and coal of which iron is the predominant element in its composition:

- $\quad$ Steel grade: $\mathrm{F}_{\mathrm{E}} 360$;

- Elastic limit: $\mathrm{f}_{\mathrm{y}}=235 \mathrm{MPa}$;

- Tensile strength: $\mathrm{f}_{\mathrm{u}}=360 \mathrm{MPa}$;

- Density: $\rho=7850 \mathrm{Kg} / \mathrm{m}^{3}$;

- Longitudinal modulus of elasticity: $\mathrm{E}=210000$ $\mathrm{MPa}$;

- Transverse modulus of elasticity: $\mathrm{G}=84000 \mathrm{MPa}$;

- Poisson's ratio: $v=0.3$.

- Reinforced concrete: it is a material constituted by the mixture of cement with aggregates (sand and stone) and water, all these components intervene in the resistance of the mixture (concrete), and we will use this material because of its resistance to compression better than to the tensile force.

- The reinforced concrete is dosed at $350 \mathrm{~kg} / \mathrm{m}^{3}$;

- Concrete of cleanliness is dosed at $150 \mathrm{~kg} / \mathrm{m}^{3}$;

- Characteristic compressive strength: $\mathrm{f}_{\mathrm{c} 28}=25 \mathrm{MPa}$;

- Characteristic tensile strength: $\mathrm{f}_{\mathrm{t} 28}=2.1 \mathrm{MPa}$;

- Density $=2500 \mathrm{~kg} / \mathrm{m}^{3}$;

- Modulus of elasticity: $\mathrm{E}=14000 \mathrm{MPa}$.

- Building envelope: considering the environmental aggressiveness and the flow of rain in the ocean division, and precisely in the village of MBORO, we will use at the ends of the vertical walls a ribbed steel cladding, "type HACIERBA 6.175.25 B ep. 0.75" and in the middle, a multi-material and multilayer filling. As for the roof cover, we will use a "HACIERCO 3 ribbed steel plate cover. 333 . 39 T ep. 0.75 " and the same for over-roofing; and in the middle of these, thermal insulation will be inserted as appropriate.

\section{Structural steel assemblies (bolting and welding)}

- Bolting is the most used means of assembly in metal construction because of its ease of implementation and the adjustment possibilities it provides on-site. For our case, we used high strength bolts class $10.9\left(f_{y}=900 \mathrm{MPa}, f_{u}=1000\right.$ $\mathrm{MPa}$ ) for the rigid assemblies of the self-stable gantries. high strength bolts include a threaded rod, a hexagonal head and a very high strength steel nut;

- Welding is an operation that consists in joining two parts of the same material with a bead of the weld made of a fillet metal, the latter serves as a binder between the two parts to be assembled.

\subsection{Thermal insulation of the Warehouse}

Using the software Autodesk Revit 2018, we get the architectural BIM model of the warehouse in Figure 1 following project requirements presented above. 


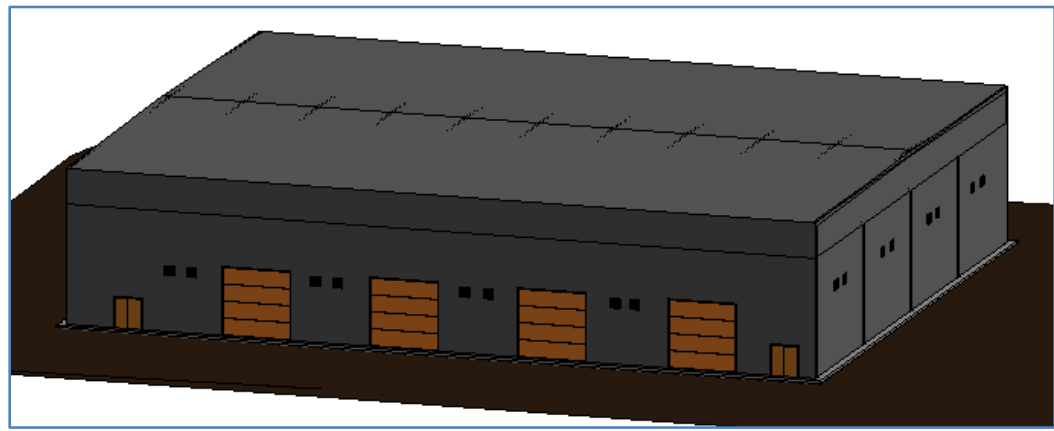

Fig-1: Architectural BIM model of the warehouse

Thermal insulation requirements pertaining to a safe conservation of agricultural products, in a hostile marine environment, compel us to design and construct roofs and walls with geometric and mechanical specificities as presented in the previous section and in
Figure 2. After elaborating computations from a validated numerical software in the civil engineering department of our school, we get the thickness of their respective layers as presented in Table 1 below.

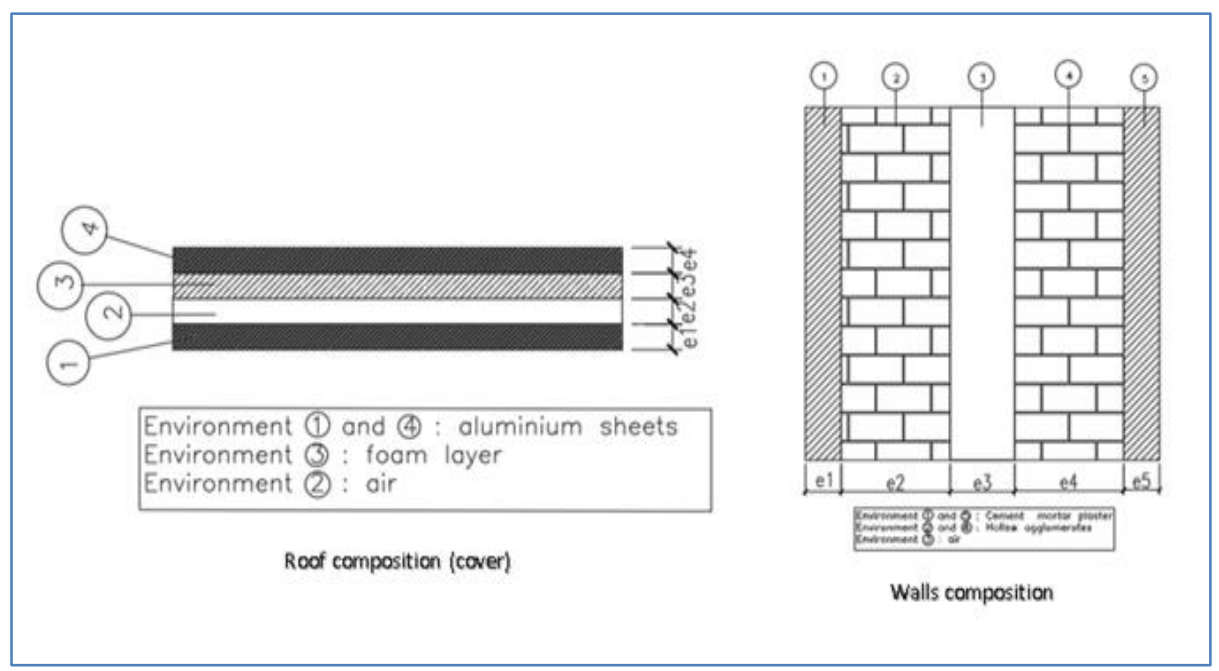

Fig-2: Composition of roof and walls for thermal insulation of the warehouse

Table-1: Thickness of layers for roof and wall of the warehouse

\begin{tabular}{|l|l|l|l|l|l|l|l|l|}
\hline e1 (m) & e2 (m) & e3 (m) & e5 (m) \\
\hline Roof & Wall & Roof & Wall & Roof & Wall & Roof & Wall & Wall \\
\hline 0.01 & 0.001 & 0.5 & 0.15 & 0.01 & 0.5 & 0.01 & 0.15 & 0.001 \\
\hline
\end{tabular}

\subsection{Structural BIM model}

The structural model will be made by transferring the information from the architectural model made in the Autodesk Revit 2018 software to the Autodesk Robot Structural Analysis (RSA) software. This transfer is done using the "export" tab where we click on "CAD formats" we choose the "DWG" format. Once in RSA, we place ourselves in the "file" tab, we click on "import", we choose "DWG". FROM there, we will go to select the file created instead in Autodesk Revit 2018. After loading the file, we will modify the parameters of the bars and select the calculation standards (see section 3.1.).

The sizing of the structural elements will be done from top to bottom. Thus, we will start by applying the loads to the different elements (See
Eurocode 1). Next, we will create the different load combinations and analyze the structure. After analysis, we will click on the "calculate" tab, so that RSA sizes the steel bars. After calculations, we obtain the results presented in Table 2 .

Next, we will select the lower end of one of the poles and click on the "sizing" tab. A drop-down menu will then appear and, in this menu, we will choose "actual reinforcement of the elements in BA". We will start by sizing the sole under node 1 and repeat the same steps for the other poles.

The "optimization" tab allows us to choose the type of optimization to apply to the sizing of the sole. Then we will enter the information of the environment. Once this is done, we will choose the appropriate 
calculation parameters for the calculation of steel sections. After calculation, the results are displayed and we can then perform a proper layout. We can then have the reinforcement plans and the calculation note printed.
The calculation notes of each of the soles are available in the software in text format. Using Revit Structure 2018 and Robot Structural Analysis 2018, we get structure of the warehouse described in Table 2 and Figures 3, 4 and 5.

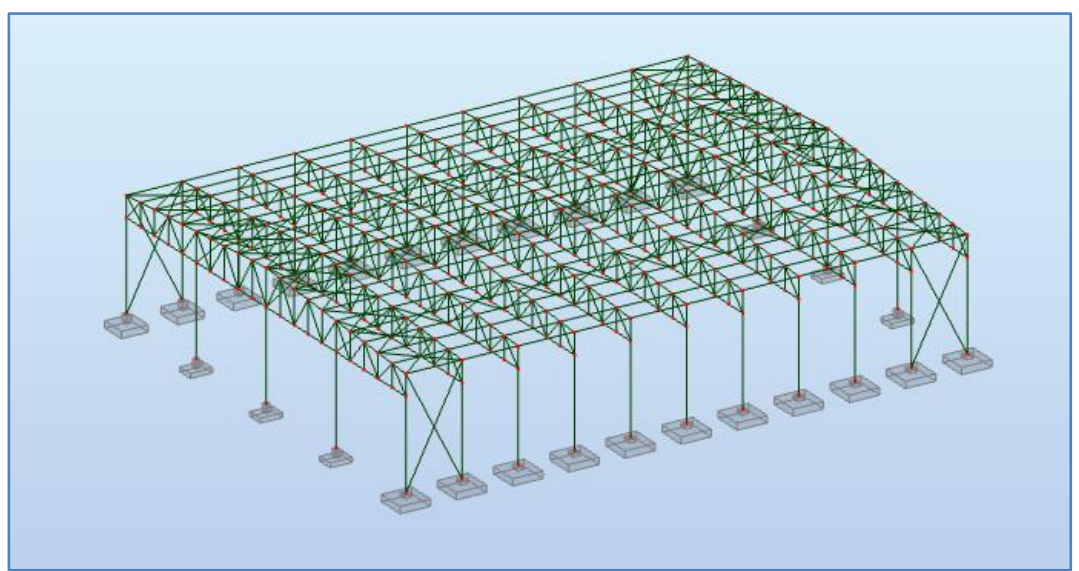

Fig-3: Structural BIM model of the warehouse

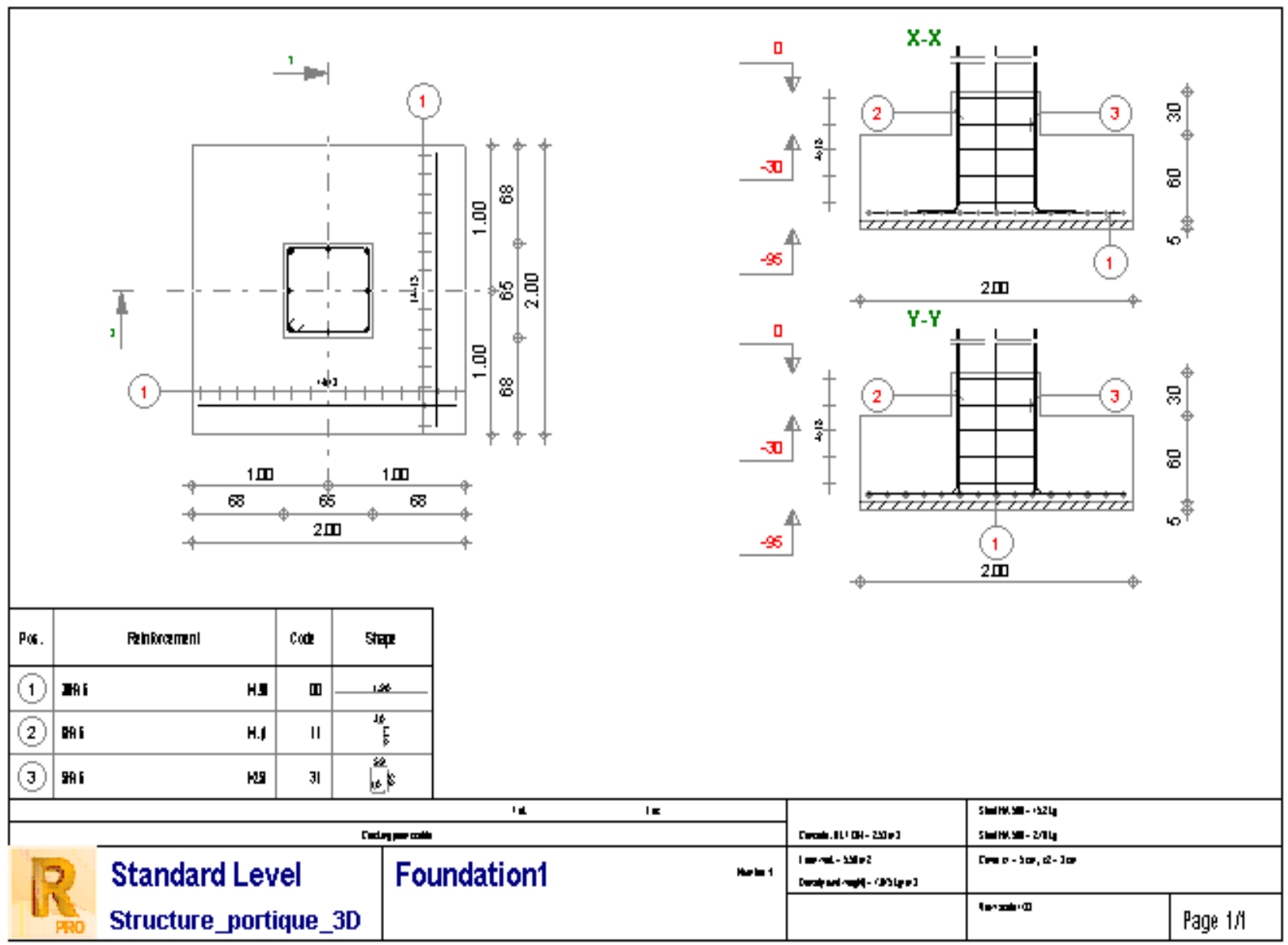

Fig-4: Detailed design of foundations of the warehouse 


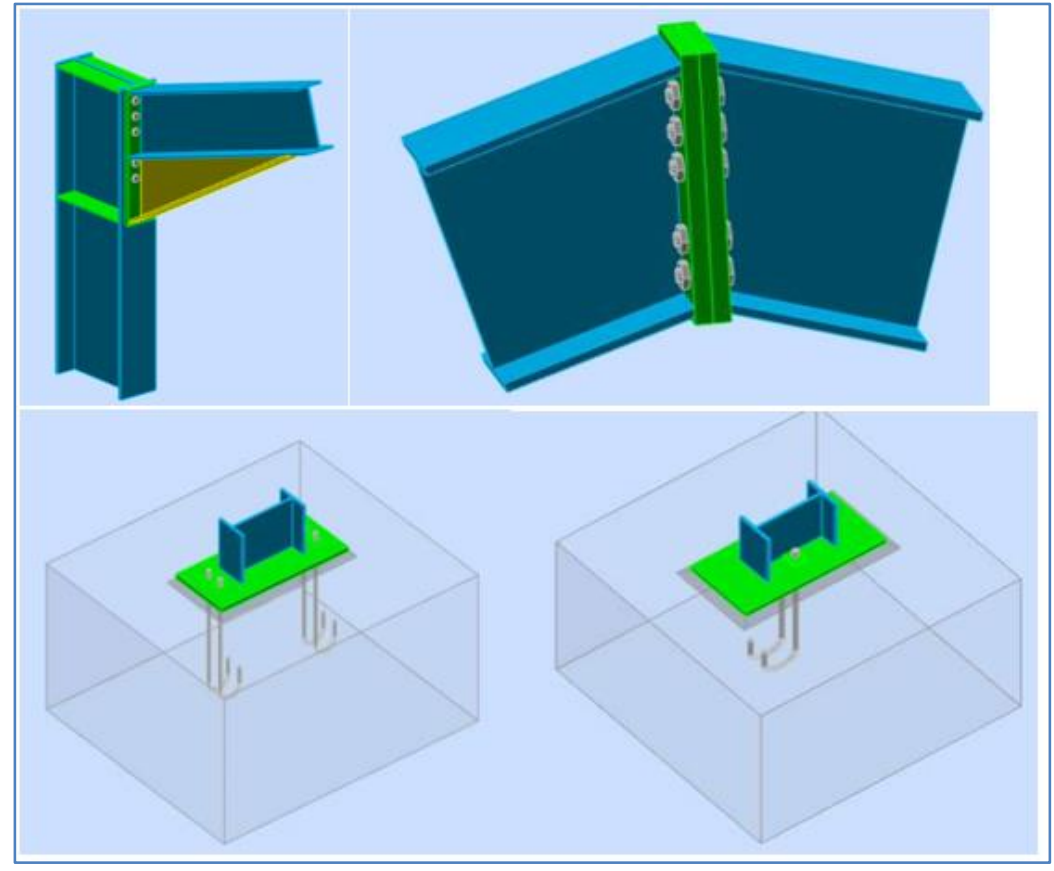

Fig-5: Assemblies of some structural elements of the warehouse

Table-2: Sections of some structural elements of the warehouse

\begin{tabular}{|l|l|l|l|l|l|l|l|l|}
\hline $\begin{array}{l}\text { Structural } \\
\text { Element }\end{array}$ & Column & $\begin{array}{l}\text { Lower } \\
\text { cord }\end{array}$ & Upper cord & $\begin{array}{l}\text { Rising } \\
\text { bars }\end{array}$ & Diagonals & Breakdown & Bracing & $\begin{array}{l}\text { Wind } \\
\text { beam }\end{array}$ \\
\hline Sections & HEA 280 & $\begin{array}{l}2 \mathrm{CAE} \\
200 \times 24\end{array}$ & $\begin{array}{l}2 \mathrm{CAE} \\
200 \times 20\end{array}$ & $\begin{array}{l}2 \mathrm{CAE} \\
120 \times 12\end{array}$ & $\begin{array}{l}2 \mathrm{CAE} \\
100 \times 8\end{array}$ & IPE 300 & $\begin{array}{l}\text { CAE } \\
25 \times 5\end{array}$ & $\begin{array}{l}\text { CAE } \\
30 \times 3\end{array}$ \\
\hline
\end{tabular}

\subsection{Coordination of 3D BIM models and interference detection \\ In our case, there was no testing for} interference detection because the overall mockup was obtained by integrating the calculation results obtained in RSA with the initial architectural mockup in Autodesk Revit 2018. To do this, we used RSA's "addons" tab, and then chose "integration with Autodesk Revit Structure." This allows us to update the existing model that will contain the information of the architectural model and the structure model. This gives us our global model.

In Autodesk Revit 2018 software, the "Schedule" tool allows us to get the quantities for each chosen item according to the chosen parameters. And, thanks to the "BIM one" option, we will be able to transfer this information to Ms. Excel to calculate the total prices and establish the DQE.

\subsection{D BIM model of the warehouse}

The "time liner" tab is the feature that will allow us to link the schedule to the 3D model. At this level, we can either create a schedule or import a schedule from an MS Project. At the end of this task, we will associate the elements of the model with the schedule thanks to the "attach" tab and specify the task that the simulator will have to perform on the element. The "simulate" tab allows us to simulate the site stages according to the work execution schedule.

Before we start attaching the schedule, we must first import the global model from Revit to Navisworks manage via the IFC format. Or directly export the model from Revit to Navisworks via the "export" option of the software. After having attached the construction schedule (imported from Ms. Project), we get the 4D model. We thus can simulate the different stages of the construction of the building as seen in figures 6 and in figure 7, ranging from the foundation design and implementation to the roofing and finishing works. This 4D model has the advantage to help the engineering team of the project owner, as well as of the constructor, to control the construction process in real time, to evaluate the contract shortcomings and to make adequate timely corrections and provisions in order to avoid any delay. 


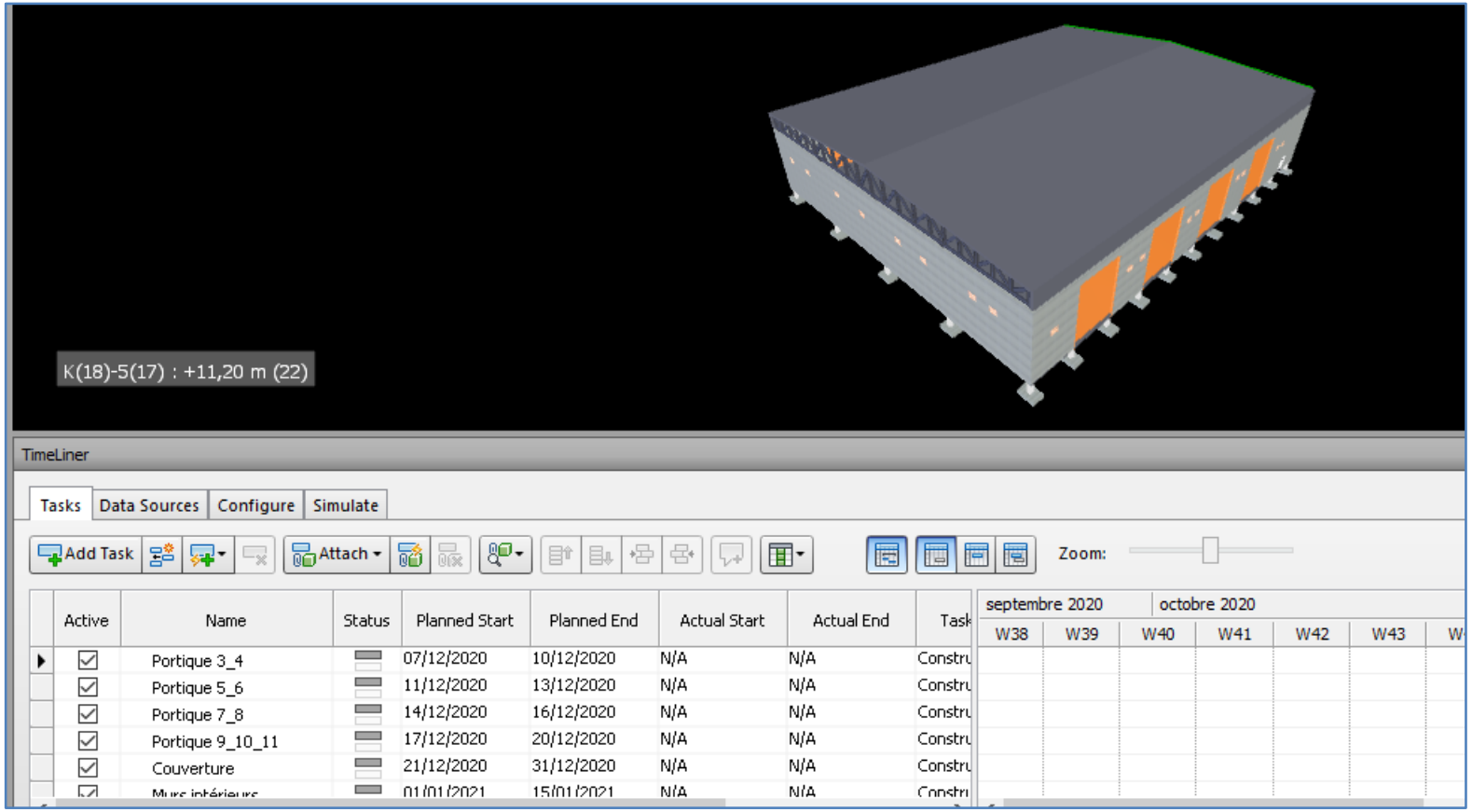

Fig-6: Illustration of 4D BIM model of the warehouse

Observations during the data collection on building management, of more than eight warehouse projects covering a storage area of nearly three hectare surface in PAK industrial zone, show that the local construction industry, for various reasons of the unknown process, is still lagging behind in BIM implementation even if engineers acknowledge its sounding benefits in terms of the control of project delay, cost overrun, timely delivery high quality material, low risks related with errors, subjectivity and inconsistency. This control is highly appreciated through the facilitation of the visualization and simulation of various project components under different environments before their implementation in the construction site. A process that also enables engineers, both now and in the future, to integrate clear project databases (seldom found locally after commissioning for post-construction modifications) right from concepts through to detailed design, procurement, and construction.

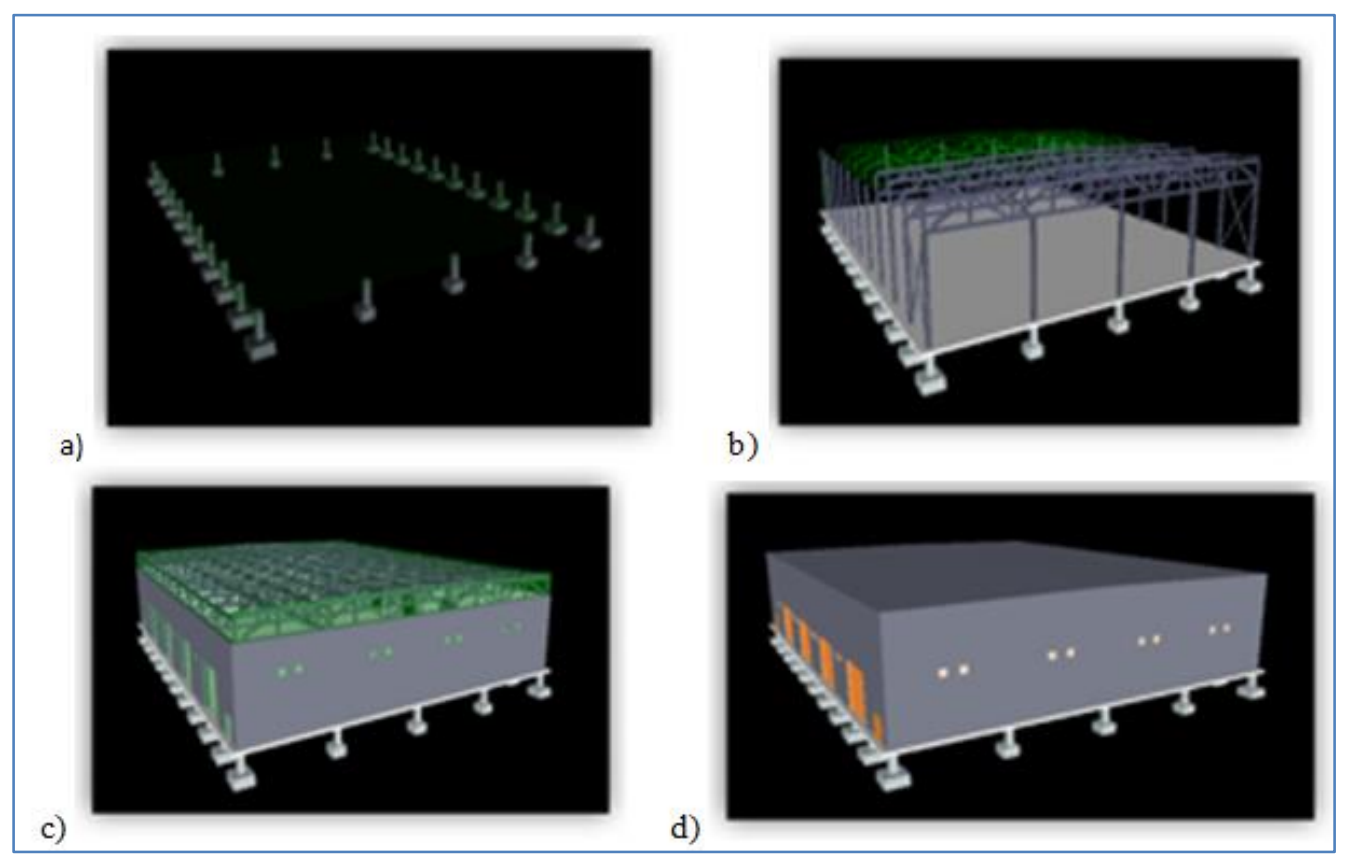

Fig-7: Simulation of construction stages with 4D BIM model of the warehouse: a) the foundation; b) the metallic frame; c) the walls; and the roofing and finishing works. 


\section{CONCLUSION}

In order to enhance the use of full potential of BIM in Cameroon, our paper proposed an approach for designing industrial warehouses in Cameroon. This approach, in six main steps, allows any local engineer versed in engineering soft wares to quickly design a consistent 4D BIM model of a warehouse for industrial purposes. With difficulties and setbacks linked with classical design and construction methods in the country, local engineers are becoming interested with the BIM concept and implementation, and efforts are being made in relation with technical universities and training centers to ease the appropriation of its substantial benefits in terms of the control of project delay, cost overrun, timely delivery high quality material, inconsistency and subjectivity in construction and information management.

However, the obtained 4D model does not take into account electrical and mechanical components of this industrial building. For further research works, we will move forward the proposed approach in order to integrate electrical and mechanical models into the 3D BIM model of the warehouse; as well as the cost estimation (5D BIM model) and environmental impacts (6D BIM model).

\section{REFERENCES}

1. Abanda, F. H., Mzyece, D., Oti, A.H., \& Manjia, M. B. (2018). A Study of the Potential of Cloud/Mobile BIM for the Management of Construction Projects. Appl. Syst. Innov., 1 (9): 2-19.

2. Buhammood, A. H., Abanda, F. H., Garstecki, P., \& Manjia, M. B. (2020). Coupling BIM and Game Engine Technologies for Construction Knowledge Enhancement. International Journal of Gaming and Computer-Mediated Simulations, 12(4).

3. Celnik, O., et Lebègue, E. (2015). BIM et Maquette Numérique pour l'architecture, le bâtiment et la construction. Groupe Eyrolles et CSTB.

4. CSTB, Centre Scientifique et Technique du Bâtiment. (1975). Règle de calcul des caractéristiques thermiques utiles des parois de construction, des déperditions de base des bâtiments et du coefficient $\mathrm{G}$ des logements et autres locaux d'habitation. Document Technique Unifié, CSTB.
5. Daniel, J. S. (2020). Design Integration Using Autodesk Revit 2020 Architecture, Structure and MEP. SDC PUBLICATIONS Better Textbooks, AIA, CSI, CDT 2020. 80 p. https://static.sdcpublications.com/pdfsample/978-163057-250-1-8.pdf

6. Eastman, C., Teicholz, P., Sacks, R., \& Liston, K. (2011). BIM Handbook : A Guide to Building Information Modeling for Owners, Managers, Designers, Engineers and Contractors. John Wileu \& Sons, Inc.

7. Hanane B., Dalila, L., (2020). Building Information Modeling (BIM) barriers in Africa versus global challenges. Conference: 2020 6th IEEE Congress on Information Science and Technology (CiSt), June 2020, 495-501, DOI: $10.1109 / \mathrm{CiSt} 49399.2021 .9357248$

8. Rho, J., Lee, H. S., \& Park, M. (2020). Automated BIM generation using drawing recognition and linetext extraction. Journal of Asian Architecture and Building Engineering, 1-13.

9. McAuley, B., Hore, A., \& West, R. (2017). BICP Global BIM study - Lessons for Ireland's BIM Programme. Reports.

10. Navisworks, S. (2018). Navisworks Simulate 2018 The Complete Guide. Open on CADD Community, Category: Autodesk 2018 https://www.caddmicrosystems.com/community/cat alog-item/navisworks-simulate-2018-the-completeguide-flexible/

11. Mbarga, R. O., \& Mpele, M. BIM REVIEW IN AEC INDUSTRY AND LESSONS FOR SUBSAHARAN AFRICA: CASE OF CAMEROON.

12. Okpwe, M. R., \& Mamba, M. (2020). Approach for Evaluation of Cost and Environmental Impacts of Buildings using BIM Objects. International Journal of Modern Engineering Research, 10(3); 27-43.

13. Fadason, R. T., Danladi, C. Z., \& Akut, K. L. (2018). Challenges Of Building Information Modelling Implementation In Africa A Case Of Nigerian Construction Industry. In FIG Congress (pp. 6-11).

14. Trehen, J.P., Boissieu, A., Valette, J.B., Teissier, S., \& Cornu, J. (2016). Guide méthodologique de rédaction d'une convention BIM. Paris. 